\title{
Perfil materno, gestacional e classificação de Robson por tipo de parto ocorridos em
} Cáceres-MT

\author{
Maternal, gestational profile and Robson classification by type of delivery occurred in Cáceres-MT \\ Perfil materno, gestacional y clasificación de Robson por tipo de entrega ocurrida en Cáceres-MT
}

Recebido: 13/12/2021 | Revisado: 17/12/2021 | Aceito: 18/12/2021 | Publicado: 02/01/2022

Cynthia Silva Santos

ORCID: https://orcid.org/0000-0001-9372-0813 Universidade do Estado de Mato Grosso, Brasil

E-mail: cynthia.silva@unemat.br

Júlia Salomé de Souza

ORCID: https://orcid.org/0000-0003-1909-6949 Universidade de Várzea Grande, Brasil

E-mail: julia.souza@univag.edu.br

Adryelle Lemes de Campos

ORCID: https://orcid.org/0000-0002-7307-6124 Universidade do Estado de Mato Grosso, Brasil E-mail: adryelle.campos@unemat.br

Shaiana Vilella Hartwig

ORCID: https://orcid.org/0000-0003-4245-2163 Universidade do Estado de Mato Grosso, Brasil E-mail: shaiana.hartwig@unemat.br

\begin{abstract}
Resumo
Introdução: O parto é uma experiência particular e importante na vida de um casal, para mulher envolve outros sentimentos por ser a principal envolvida, assim, a enfermagem obstétrica pode ser um potencial facilitador nas ações de educação e saúde durante o ciclo gravídico puerperal, para o empoderamento da mulher. Objetivo: Analisar o perfil materno, gestacional e a escala de Robson por tipo de partos ocorridos em Cáceres-MT entre os anos de 2015 a 2019. Método: Estudo epidemiológico descritivo, analítico, longitudinal, retrospectivo de natureza quantitativa através de dados secundários do banco de dados do DATASUS. Resultados e discussão: Os resultados mostram semelhança entre o perfil materno e obstétrico das puérperas independente da via de parto, na escala de Robson os partos normais tiveram maiores taxas nos grupos 3, 1 e 10 e nos partos cesáreos prevaleceu os grupos 5, 1 e 10 . Conclusão: Foi possível traçar o perfil socioeconômico e obstétrico das puérperas usuárias do serviço obstétrico do município de Cáceres, além de avaliar pela classificação de Robson que a maioria da população estudada é elegível para o parto normal conforme seu perfil obstétrico, sendo fundamental profissionais capacitados e condições adequadas para que isso ocorra.
\end{abstract}

Palavras-chave: Perfil epidemiológico; Classificação de Robson; Cesárea; Parto normal.

\begin{abstract}
Introduction: Childbirth is a particular and important experience in the life of a couple, for women it involves other feelings for being the main one involved, thus, obstetric nursing can be a potential facilitator in education and health actions during the pregnancy-puerperal cycle, for the empowerment of women. Objective: To analyze the maternal and gestational profile and the Robson scale by type of births that took place in Cáceres-MT between 2015 and 2019. Method: Descriptive, analytical, longitudinal, retrospective epidemiological study of a quantitative nature using secondary data from the DATASUS database. Results and discussion: The results show similarity between the maternal and obstetric profile of postpartum women regardless of the mode of delivery, on the Robson scale, normal deliveries had higher rates in groups 3,1 and 10 and in cesarean deliveries, groups 5, 1 prevailed and 10. Conclusion: It was possible to trace the socioeconomic and obstetric profile of postpartum women using the obstetric service in the municipality of Cáceres, in addition to evaluating by the Robson classification that the majority of the population studied is eligible for vaginal delivery according to their obstetric profile, which is essential trained professionals and adequate conditions for this to occur.
\end{abstract}

Keywords: Epidemiological profile; Robson classification; Cesarean; Normal birth.

\section{Resumen}

Introducción: El parto es una experiencia particular e importante en la vida de una pareja, para la mujer involucra otros sentimientos por ser la principal involucrada, por lo que la enfermería obstétrica puede ser una potencial facilitadora en las acciones de educación y salud durante el ciclo embarazo-puerperal. para el empoderamiento de la 
mujer. Objetivo: Analizar el perfil materno y gestacional y la escala de Robson por tipo de partos ocurridos en Cáceres-MT entre 2015 y 2019. Método: Estudio epidemiológico descriptivo, analítico, longitudinal, retrospectivo, de carácter cuantitativo, utilizando datos secundarios de la base de datos DATASUS. Resultados y discusión: Los resultados muestran similitud entre el perfil materno y obstétrico de las mujeres posparto independientemente del modo de parto, en la escala de Robson, los partos normales tuvieron tasas más altas en los grupos 3, 1 y 10 y en las cesáreas, grupos 5, 1 prevalecieron y 10. Conclusión: Se logró rastrear el perfil socioeconómico y obstétrico de las puérperas que utilizan el servicio de obstetricia en el municipio de Cáceres, además de evaluar por la clasificación de Robson que la mayoría de la población estudiada es elegible para parto vaginal según a su perfil obstétrico, el cual es imprescindible profesionales capacitados y condiciones adecuadas para que esto ocurra.

Palabras clave: Perfil epidemiológico; Clasificación de Robson; Cesárea; Parto normal.

\section{Introdução}

O parto é uma experiência particular e importante na vida de um casal, para mulher envolve outros sentimentos por ser a principal envolvida. Esse acontecimento abarca toda a família, amigos, e vem trazendo novas descobertas e novos hábitos e experiências de vida. Esse momento pode gerar uma experiência positiva ou negativa aos envolvidos nesse processo dependendo de como esse foi conduzido (Fujita \& Shimo, 2014).

Existem vários tipos de trabalho de parto e partos, porém os mais conhecidos e utilizados são os partos normais e partos cesáreos. Conforme nos relatam Pereira et al. (2016, p. 06) sobre o parto normal:

O parto normal é a maneira mais segura e saudável de ter filhos e, por isso, deve ser estimulado e realizado através de uma assistência humanizada, segura e de qualidade. [...]. Durante o trabalho de parto, líquidos devem ser oferecidos, além de um suporte emocional, oferecendo informações sobre os procedimentos realizados e encorajar a posição não deitada, deve-se também dar liberdade de posição e movimento à parturiente.

As fases do trabalho de parto normal acontecem de forma gradativa, onde ocorre a dilatação do colo do útero, período expulsivo e a saída da placenta. Normalmente, o trabalho de parto começa naturalmente entre as 37 e as 40 semanas de gestação (Brasil, 2005).

Em decorrência do avanço da tecnologia, o parto cesáreo, cirurgia realizada para resolver situações obstétricas de risco, começou a ser utilizado de forma abusiva, com o argumento errôneo de ser mais seguro em relação ao parto normal. Vale salientar que o parto cesáreo é definido como a retirada do feto através de uma incisão na parede abdominal (laparotomia) e na parede uterina (histerectomia). Em geral, a cesariana é realizada quando o trabalho de parto está contra indicado ou quando não é provável que o parto vaginal seja realizado com segurança (Marques, Dias, Azevedo, 2006)

Por várias vezes o modo assistencial inapropriado vem provocando cada vez mais o aumento do número de cesárias desnecessárias, causando prejuízo a saúde física e mental da mulher, impedindo-a de viver o processo fisiológico parturitivo (Nakano et al., 2016).

Além de a mortalidade materna, por sua vez, parece aumentar em taxas de cesarianas superiores a $15 \%$, sendo estimada em 7,8/100.000 para $15 \%$ de cesarianas, 7,9/100.000 para 20\%, 8.4\%/100.000 para 25\% e 8,8/100.000 para razão de cesariana de $30 \%$, tendo impacto contrário ao muitas vezes esperado (Ye et al., 2014).

A fim de entender os fatores que levam as parturientes a optarem pelo parto cesáreo, o estudo realizado por Chiavegatto Filho (2013) afirma que a maioria das cesarianas não são mais realizadas com a intenção de salvar a vida do bebê em caso de óbito materno, mas sim, de atender a uma complexa variedade de necessidades e justificativas, tais como: diminuição da dor, preferência entre os médicos, complicações no parto, experiências bem sucedidas nos partos anteriores, assim como aproveitar o procedimento para fazer laqueadura.

Assim, fatores sociais e econômicos como idade, situação financeira, raça/cor, escolaridade e estado civil influenciam tanto no tipo de hospital quanto na escolha da via de parto pela gestante. Levando em consideração que a maior parte das 
mulheres brasileiras utilizam o sistema único de saúde (SUS), essas mulheres não têm a oportunidade de escolher o médico que irá acompanhá-la, tampouco de escolher o parto de sua preferência (Patah \& Malik, 2011; Gama et al., 2014).

Acredita-se também que este fato esteja vinculado a diversos fatores tais como: o número de consultas realizadas pela gestante, a cobertura da assistência de enfermagem, a qualidade dos serviços prestados, entre outros fatores. Outro fato visto é que todas as gestantes que optaram por fazer suas consultas de pré-natal no setor privado, se restringiam às consultas médicas, não atuando naquele momento outros profissionais. (Martins et al., 2018).

Para estudar esse crescimento do número de cesarianas no mundo foi criada a classificação de Robson, em 2001, pelo médico irlandês Michael Robson, tendo como objetivo principal, a identificação dos grupos de mulheres clinicamente significativas, onde possuem diferenças nas taxas de cesárea, permitindo assim que possa haver comparações na mesma instituição durante certo período de tempo, ou então entre instituições diferentes (FIOCRUZ, 2018).

Os grupos são formados por cinco características obstétricas, sendo elas: paridade (nulípara ou multípara com e sem cesárea anterior), início do parto (espontâneo, induzido ou cesárea antes do início do trabalho de parto), idade gestacional (prétermo ou termo), apresentação/situação fetal (cefálica, pélvica ou transversa) e número de fetos (único ou múltiplo). A flexibilidade dessa classificação permite melhor entendimento das práticas obstétricas locais e da contribuição específica de cada grupo, permitindo estratégias de saúde pública direcionadas para a redução do parto cesáreo. (Moura et al., 2017)

Frente a isso, destaca-se a responsabilidade da enfermagem em atuar na reeducação das próprias pacientes explicando a elas questões inerentes ao parto natural como seu processo de humanização e todos os métodos para alívio das dores, concentrando sua ação na mudança de atitude e informação da gestante, pois, ao oferecer conhecimento as parturientes, elas poderão opinar com segurança sobre a melhor via de parto para elas (Medina, 2003).

O objetivo desta pesquisa será analisar o perfil materno, gestacional e a escala de Robson por tipo de partos ocorridos em Cáceres-MT entre os anos de 2015 a 2019.

\section{Metodologia}

\subsection{Tipo de estudo}

Estudo epidemiológico descritivo, analítico, longitudinal, retrospectivo de natureza quantitativa através de dados secundários do banco de dados do DATASUS dos tipos de partos no período de 2015 a 2019, no município de Cáceres-MT.

Segundo o Dicionário de Epidemiologia de Porta (2009), epidemiologia é o estudo da ocorrência e distribuição de eventos referente à saúde em populações específicas, englobando o estudo dos fatores determinantes que motivaram tais eventos e o uso desse conhecimento para controlar os problemas de saúde.

Um estudo descritivo busca descrever a definição de aspectos semiológicos, etiológicos, fisiopatológicos e epidemiológicos de uma doença. São utilizados para entender doença ou agravo à saúde, analisando a sua distribuição no tempo, no espaço e conforme particularidades (Haddad, 2004).

Estudos analíticos são aqueles delineados para examinar a existência de associação entre uma exposição a uma doença ou condição relacionada à saúde. (Fontelles, 2009)

Haddad (2004) descreve o estudo longitudinal destinado a estudar um processo ao longo do tempo para investigar mudanças, ou seja, refletem uma sequência de fatos. Podem ser aplicados individualmente em seres humanos, células em cultura, microorganismos, populações humanas completas ou organizações defensoras de saúde. Os estudos longitudinais podem ser prospectivos ou retrospectivos (Bailar et al., 1994)

Realiza-se o estudo retrospectivo a partir de registros do passado, e é acompanhado a partir daquele momento até o presente. É necessário que haja credibilidade nos dados de registros a serem utilizados, em relação à exposição do fator e a 
sua intensidade, tal como pela ocorrência da doença, situação clínica ou do óbito por esse motivo (Fletcher et al., 2003; Haddad, 2004).

Segundo Fontelles et al. (2009) a pesquisa quantitativa utiliza uma metodologia baseada em números, métricas e cálculos matemáticos. Emprega rígidos recursos e técnicas estatísticas para classificá-los e analisá-los, tais como a porcentagem, a média, o desvio padrão, o coeficiente de correlação e as regressões, entre outros. Com esse tipo de método, é possível obter respostas objetivas, assim os estudos quantitativos são mais indicados para o planejamento de ações coletivas, pois seus resultados são passíveis de generalização, principalmente quando as amostras pesquisadas representam, com fidelidade, a população de onde foram retiradas.

\section{2 Área de Estudo}

O local de pesquisa será a cidade de Cáceres - MT, localizada na mesorregião Centro-Sul do estado e na microrregião do Alto Pantanal. Segundo o Instituto Brasileiro de Geografia e Estatística (IBGE), estima-se uma população de 94.861 habitantes. O Índice de Desenvolvimento Humano Municipal no ano de 2010 foi 0,708 (IBGE, 2010).

O município mantém atualmente dois hospitais, sendo eles o Hospital Regional Dr. Antônio Fontes e o Hospital São Luiz, dois prontos atendimentos, seis postos de saúde, dezesseis unidades básicas de saúde, entre demais consultórios, clínicas e centros de atenção compondo um total de 189 estabelecimentos de saúde registrados no cadastro nacional de estabelecimentos de saúde (CNES, 2021).

O Hospital São Luiz (HSL) é referência em gestação e parto de alto risco para 22 municípios da Região Oeste do estado de Mato Grosso, incluindo o país vizinho, a Bolívia. Em média nascem 200 bebês por mês, são 5 a 7 partos realizados por dia. O HSL é também é referência em atendimento ao recém-nascido que necessite de UTI Neonatal sendo capacitada para o atendimento aos prematuros, recém-nascido de alto risco, gemelares ou que necessitem de cuidados especiais, dentro de uma proposta de humanização da assistência (Hospital São Luiz, 2020).

No ano de 2015, o Hospital Regional Dr. Antônio Fontes dispôs do Programa de Residência Médica na área de Ginecologia e Obstetrícia com duração de três anos, onde utilizou o campo disponibilizado pelo HSL.

\subsection{População do estudo}

A população do estudo será constituída pelas mulheres que tiveram partos realizados no período 2015-2019 no município de Cáceres.

\subsection{Procedimento de coleta de dados}

Os dados serão coletados a partir do registro do Sistema de Informação de Nascidos Vivos (SINASC) de partos por ocorrência do município de Cáceres-MT no período de 2015 a 2019, disponibilizada pelo Ministério da Saúde no endereço eletrônico DATASUS (Disponível em: <http://www2.datasus.gov.br/DATASUS/index.php?area=02>) através do qual será possível coletar todas as variáveis necessárias para o desenvolvimento do estudo.

No ano de 2012 a declaração de nascido vivo passou por mudanças propostas pelo Ministério da Saúde, o DATASUS mesclou os dados, dessa forma, a fim de ter dados mais fidedignos optou-se na realização deste trabalho utilizar dados que foram capturados após a substituição total dessas declarações, abrangendo assim o período de 2015 a 2019.

Serão estudadas as variáveis locais de ocorrência, faixa etária materna, instrução da mãe, estado civil da mãe, local de residência da mãe, número de consultas pré-natal, duração da gestação, tipo de gravidez e adequação quantitativa do de prénatal, todas as variáveis serão coletadas por tipo de parto. 


\subsection{Análise de dados}

Para análise descritiva será realizado cálculo de tendência central e dispersão para variáveis quantitativas e para variáveis qualitativas será realizado frequência absoluta e relativa. Para o cálculo da taxa de natalidade por tipo de parto foi utilizada a seguinte fórmula:

\section{$\frac{\text { Número de nascidos vivos por tipo de parto }}{\text { Número de nascidos vivos totais }} \times 1000$}

Os dados foram trabalhados no Microsoft Office Excel. A partir da análise e interpretação de todos os dados, serão construídos tabelas e gráficos com a finalidade de compreender os dados levantados.

\subsection{Considerações éticas}

Por se tratar de um estudo com dados secundários de um banco de domínio público, não será necessário submeter o projeto ao Comitê de Ética em Pesquisa (CEP).

\section{Resultados e Discussão}

A ocorrência de partos cesáreos foi maior do que parto normal ocorridos em Cáceres entre os anos de 2015 a 2019. Observar-se um aumento gradativo das taxas de parto cesáreo alcançando seu pico no ano de 2018 (786,20 a cada 1000 nascidos vivos) e em seguida havendo uma queda no ano de 2019 (695,75 a cada 1000 nascidos vivos). Contrário a esses números, em relação ao parto normal é notório o declínio das taxas, de forma que o ano de 2018 obteve a menor taxa do período analisado (213,80 a cada 1000 nascidos vivos) (Figura 1).

Figura 1. Taxa de natalidade por 1000 nascidos vivos segundo tipo de parto em Cáceres-MT, 2015 a 2019.

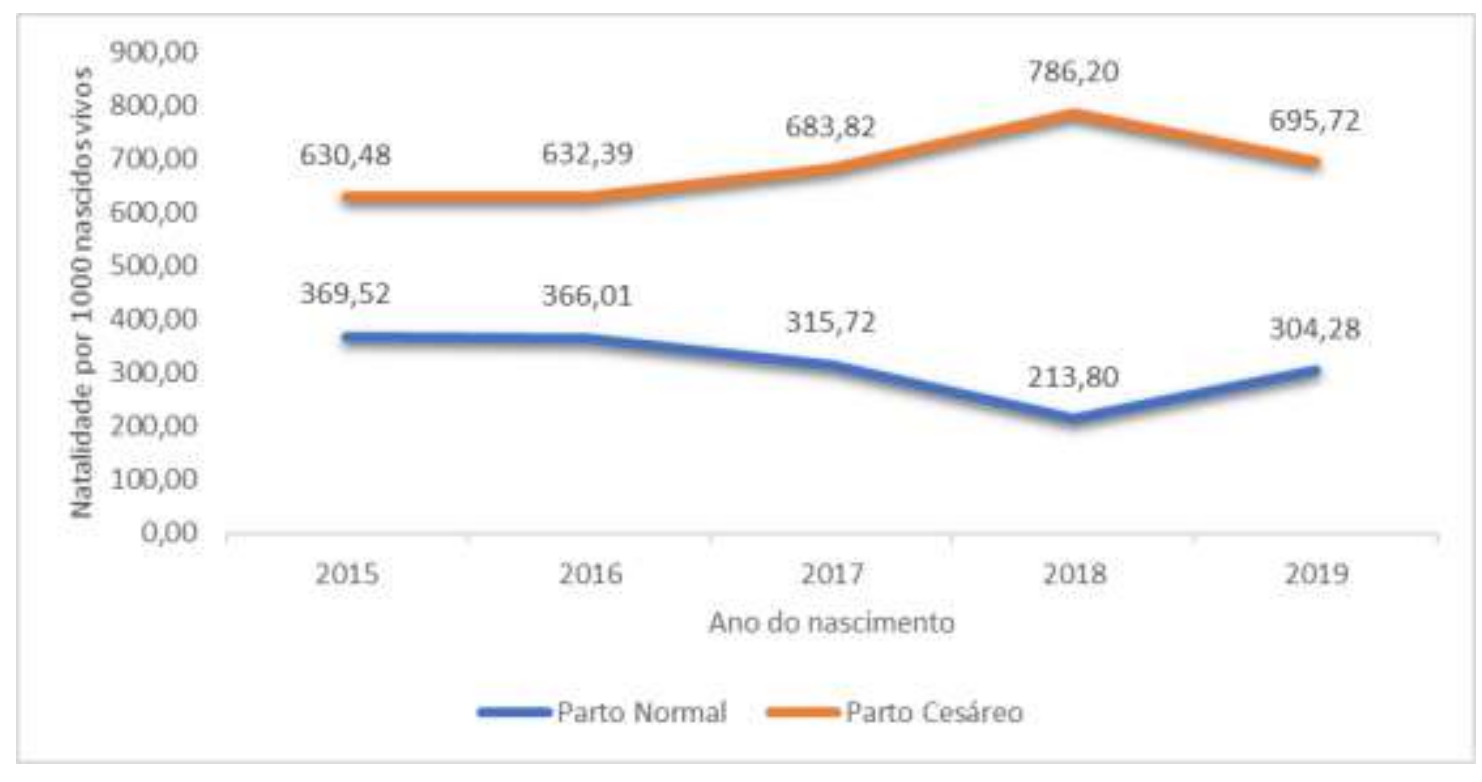

Fonte: DATASUS (2021).

De acordo com a Organização Mundial de Saúde (2005) estima-se entre $10 \%$ e $15 \%$ a proporção de cesáreas necessárias por motivos médicos. Percebe-se que no período analisado as taxas de cesáreas foram superiores às taxas de parto normal, o que é contrário ao que sugerido pela OMS, enfatizando assim que as taxas de cesárea continuam a aumentar mesmo sem uma compreensão clara das principais causas e suas consequências. Apontando a necessidade de uma análise detalhada das taxas de cesárea visando identificar os fatores que contribuíram para estes números.

Observa-se que o percentual de cesáreas foram crescentes conforme o aumento da faixa etária materna. As gestantes 
adolescentes (15 a 19 anos) e adultas (20 a 24 anos), apresentaram no ano de 2017 percentual de 16,5\% e 27,0\%, respectivamente. Em contrapartida, os percentuais de partos normais caem de acordo com a idade da mãe, no ano de 2015 às gestantes de 25 a 29 anos e as gestantes de 30 a 34 anos, apresentaram percentuais de 24,8\% e 11,3\%, respectivamente.

Nos dois tipos de partos prevaleceu a instrução da mãe de 8 a 11 anos. As mães com instrução com 12 anos a mais têm uma porcentagem maior nos partos cesáreos $(28,0 \%)$ do que nos partos normais $(9,0 \%)$ no ano de 2016.

Em relação ao estado civil, as gestantes solteiras têm um percentual maior nos partos normais. No ano de 2015 , às mães solteiras de parto normal e as de parto cesáreo, apresentaram percentual de 68,0\% e 87,6\%, respectivamente. Já as mulheres casadas tiveram um percentual maior no parto cesáreo, no mesmo ano de 2015 às mulheres de PN e de PC, exibiram taxas de $10,2 \%$ e $26,7 \%$, simultaneamente (Tabela 1 ).

Tabela 1. Frequência absoluta e percentual de partos de acordo com as características maternas por tipo de parto no município de Cáceres-MT, 2015 a 2019.

\begin{tabular}{|c|c|c|c|c|c|c|c|c|c|c|}
\hline \multirow[t]{2}{*}{ Variáveis } & \multicolumn{2}{|c|}{2015} & \multicolumn{2}{|c|}{2016} & \multicolumn{2}{|c|}{2017} & \multicolumn{2}{|c|}{2018} & \multicolumn{2}{|c|}{2019} \\
\hline & PN & PC & PN & PC & PN & PC & PN & PC & PN & PC \\
\hline \multicolumn{11}{|l|}{ Faixa Etária } \\
\hline 10 a 14 anos & $\begin{array}{c}13 \\
(1,8 \%)\end{array}$ & $13(1,0 \%)$ & $12(1,7 \%)$ & $14(1,2 \%)$ & $\begin{array}{c}7 \\
(1,0 \%)\end{array}$ & $11(0,7 \%)$ & $\begin{array}{c}7 \\
(1,4 \%)\end{array}$ & $\begin{array}{c}17 \\
(0,9 \%)\end{array}$ & $\begin{array}{c}11 \\
(1,5 \%)\end{array}$ & $\begin{array}{c}16 \\
(0,9 \%)\end{array}$ \\
\hline 15 a 19 anos & $\begin{array}{c}210 \\
(28,3 \%)\end{array}$ & $\begin{array}{c}199 \\
(15,7 \%)\end{array}$ & $\begin{array}{c}177 \\
(25,8 \%)\end{array}$ & $\begin{array}{c}197 \\
(16,6 \%)\end{array}$ & $\begin{array}{c}182 \\
(26,7 \%)\end{array}$ & $\begin{array}{c}243 \\
(16,5 \%)\end{array}$ & $\begin{array}{c}121 \\
(23,8 \%)\end{array}$ & $\begin{array}{c}339 \\
(18,1 \%)\end{array}$ & $\begin{array}{c}185 \\
(25,0 \%)\end{array}$ & $\begin{array}{c}268 \\
(15,8 \%)\end{array}$ \\
\hline 20 a 24 anos & $\begin{array}{c}217 \\
(29,2 \%)\end{array}$ & $\begin{array}{c}287 \\
(22,7 \%)\end{array}$ & $\begin{array}{c}217 \\
(31,6 \%)\end{array}$ & $\begin{array}{c}313 \\
(26,4 \%)\end{array}$ & $\begin{array}{c}201 \\
(29,5 \%)\end{array}$ & $\begin{array}{c}398 \\
(27,0 \%)\end{array}$ & $\begin{array}{c}161 \\
(31,7 \%)\end{array}$ & $\begin{array}{c}436 \\
(23,3 \%)\end{array}$ & $\begin{array}{c}235 \\
(31,8 \%)\end{array}$ & $\begin{array}{c}400 \\
(23,6 \%)\end{array}$ \\
\hline 25 a 29 anos & $\begin{array}{c}184 \\
(24,8 \%)\end{array}$ & $\begin{array}{c}328 \\
(25,9 \%)\end{array}$ & $\begin{array}{c}152 \\
(22,1 \%)\end{array}$ & $\begin{array}{c}299 \\
(25,2 \%)\end{array}$ & $\begin{array}{c}153 \\
(22,5 \%)\end{array}$ & $\begin{array}{c}331 \\
(22,4 \%)\end{array}$ & $\begin{array}{c}118 \\
(23,2 \%)\end{array}$ & $\begin{array}{c}439 \\
(23,5 \%)\end{array}$ & $\begin{array}{c}149 \\
(20,1 \%)\end{array}$ & $\begin{array}{c}417 \\
(24,6 \%)\end{array}$ \\
\hline 30 a 34 anos & $\begin{array}{c}84 \\
(11,3 \%)\end{array}$ & $\begin{array}{c}284 \\
(22,4 \%)\end{array}$ & $\begin{array}{c}81 \\
(11,8 \%)\end{array}$ & $\begin{array}{c}232 \\
(19,5 \%)\end{array}$ & $\begin{array}{c}94 \\
(13,8 \%)\end{array}$ & $\begin{array}{c}293 \\
(19,9 \%)\end{array}$ & $\begin{array}{c}65 \\
(12,8 \%)\end{array}$ & $\begin{array}{c}404 \\
(21,6 \%)\end{array}$ & $\begin{array}{c}106 \\
(14,3 \%)\end{array}$ & $\begin{array}{c}332 \\
(19,6 \%)\end{array}$ \\
\hline 35 a 39 anos & $\begin{array}{c}22 \\
(3,0 \%)\end{array}$ & $\begin{array}{c}121 \\
(9,6 \%)\end{array}$ & $36(5,2 \%)$ & $\begin{array}{c}116 \\
(9,8 \%)\end{array}$ & $34(5,0 \%)$ & $\begin{array}{c}167 \\
(11,3 \%)\end{array}$ & $32(6,3 \%)$ & $\begin{array}{c}194 \\
(10,4 \%)\end{array}$ & $\begin{array}{c}44 \\
(5,9 \%)\end{array}$ & $\begin{array}{c}207 \\
(12,2 \%)\end{array}$ \\
\hline 40 a 44 anos & $\begin{array}{c}10 \\
(1,3 \%)\end{array}$ & $34(2,7 \%)$ & $10(1,5 \%)$ & $15(1,3 \%)$ & $10(1,5 \%)$ & $28(1,9 \%)$ & $\begin{array}{c}4 \\
(0,8 \%)\end{array}$ & $\begin{array}{c}37 \\
(2,0 \%)\end{array}$ & $\begin{array}{c}10 \\
(1,4 \%)\end{array}$ & $\begin{array}{c}51 \\
(3,0 \%)\end{array}$ \\
\hline 45 a 49 anos & $1(0,1 \%)$ & $0(0,00 \%)$ & $\begin{array}{c}2 \\
(0,3 \%)\end{array}$ & $\begin{array}{c}1 \\
(0,1)\end{array}$ & $0(0,00 \%)$ & $\begin{array}{c}3 \\
(0,2 \%)\end{array}$ & $0(0,00 \%)$ & $\begin{array}{c}2 \\
(0,1 \%)\end{array}$ & $\begin{array}{c}0 \\
(0,00 \%)\end{array}$ & $\begin{array}{c}1 \\
(0,1 \%)\end{array}$ \\
\hline 50 a 54 anos & $1(0,1 \%)$ & $0(0,00 \%)$ & $0(0,00 \%)$ & $0(0,00 \%)$ & $0(0,00 \%)$ & $\begin{array}{c}1 \\
(0,1 \%)\end{array}$ & $0(0,00 \%)$ & $\begin{array}{c}0 \\
(0,00 \%)\end{array}$ & $\begin{array}{c}0 \\
(0,00 \%)\end{array}$ & $\begin{array}{c}0 \\
(0,00 \%)\end{array}$ \\
\hline \multicolumn{11}{|l|}{$\begin{array}{l}\text { Instrução da } \\
\text { mãe }\end{array}$} \\
\hline Nenhuma & $3(0,4 \%)$ & $6(0,5 \%)$ & $2(0,3 \%)$ & $0(0,0 \%)$ & $1(0,1 \%)$ & $5(0,3 \%)$ & $0(0,0 \%)$ & $5(0,3 \%)$ & $6(0,8 \%)$ & $0(0,0 \%)$ \\
\hline 1 a 3 anos & $\begin{array}{c}20 \\
(2,7 \%)\end{array}$ & $19(1,5 \%)$ & $22(3,2 \%)$ & $19(1,6 \%)$ & $15(2,2 \%)$ & $22(1,5 \%)$ & $10(2,0 \%)$ & $29(1,6 \%)$ & $9(1,2 \%)$ & $12(0,7 \%)$ \\
\hline 4 a 7 anos & $\begin{array}{c}146 \\
(19,7 \%)\end{array}$ & $\begin{array}{c}130 \\
(10,3 \%)\end{array}$ & $\begin{array}{c}125 \\
(18,2 \%)\end{array}$ & $\begin{array}{c}133 \\
(11,2 \%)\end{array}$ & $\begin{array}{c}125 \\
(18,4 \%)\end{array}$ & $\begin{array}{c}166 \\
(11,3 \%)\end{array}$ & $\begin{array}{c}79 \\
(15,6 \%)\end{array}$ & $183(9,8 \%)$ & $99(13,4 \%)$ & $116(6,9 \%)$ \\
\hline 8 a 11 anos & $\begin{array}{c}499 \\
(67,3 \%)\end{array}$ & $\begin{array}{c}765 \\
(60,4 \%)\end{array}$ & $\begin{array}{c}476 \\
(69,3 \%)\end{array}$ & $\begin{array}{c}699 \\
(58,9 \%)\end{array}$ & $\begin{array}{c}458 \\
(67,3 \%)\end{array}$ & $\begin{array}{c}866 \\
(58,7 \%)\end{array}$ & $\begin{array}{c}358 \\
(\mathbf{7 0 , 5 \%})\end{array}$ & $\begin{array}{c}1149 \\
(61,5 \%)\end{array}$ & $\begin{array}{c}530 \\
(71,6 \%)\end{array}$ & $\begin{array}{c}1079 \\
(63,8 \%)\end{array}$ \\
\hline 12 anos e mais & $\begin{array}{c}74 \\
(10,0 \%)\end{array}$ & $\begin{array}{c}346 \\
(27,3 \%)\end{array}$ & $62(9,0 \%)$ & $\begin{array}{c}332 \\
(28,0 \%)\end{array}$ & $\begin{array}{c}79 \\
(11,6 \%)\end{array}$ & $\begin{array}{c}414 \\
(28,1 \%)\end{array}$ & $\begin{array}{c}59 \\
(11,6 \%)\end{array}$ & $\begin{array}{c}501 \\
(26,8 \%)\end{array}$ & $96(13,0 \%)$ & $\begin{array}{c}483 \\
(28,5 \%)\end{array}$ \\
\hline Ignorado & $0(0,0 \%)$ & $0(0,0 \%)$ & $0(0,0 \%)$ & $4(0,3 \%)$ & $3(0,4 \%)$ & $2(0,1 \%)$ & $2(0,4 \%)$ & $1(0,1 \%)$ & $0(0,0 \%)$ & $2(0,1 \%)$ \\
\hline \multicolumn{11}{|l|}{ Estado civil } \\
\hline Solteira & $\begin{array}{c}650 \\
(87,6 \%)\end{array}$ & $\begin{array}{c}861 \\
(68,0 \%)\end{array}$ & $\begin{array}{c}\mathbf{5 7 6} \\
(\mathbf{8 3 , 8 \%})\end{array}$ & $\begin{array}{c}854 \\
(71,9 \%)\end{array}$ & $\begin{array}{c}538 \\
(\mathbf{7 9 , 0 \%})\end{array}$ & $\begin{array}{c}988 \\
(67,0 \%)\end{array}$ & $\begin{array}{c}315 \\
(62,0 \%)\end{array}$ & $\begin{array}{c}1276 \\
(68,3 \%)\end{array}$ & $\begin{array}{c}566 \\
(76,5 \%)\end{array}$ & $\begin{array}{c}1179 \\
(69,7 \%)\end{array}$ \\
\hline Casada & $\begin{array}{c}76 \\
(10,2 \%)\end{array}$ & $\begin{array}{c}338 \\
(26,7 \%)\end{array}$ & $\begin{array}{c}71 \\
(10,3 \%)\end{array}$ & $\begin{array}{c}270 \\
(22,7 \%)\end{array}$ & $\begin{array}{c}92 \\
(13,5 \%)\end{array}$ & $\begin{array}{c}375 \\
(25,4 \%)\end{array}$ & $\begin{array}{c}69 \\
(13,6 \%)\end{array}$ & $\begin{array}{c}452 \\
(24,2 \%)\end{array}$ & $\begin{array}{c}109 \\
(14,7 \%)\end{array}$ & $\begin{array}{c}433 \\
(25,6 \%)\end{array}$ \\
\hline Viúva & $1(0,1 \%)$ & $3(0,2 \%)$ & $1(0,1 \%)$ & $4(0,3 \%)$ & $0(0,0 \%)$ & $2(0,1 \%)$ & $0(0,0 \%)$ & $5(0,3 \%)$ & $0(0,0 \%)$ & $2(0,1 \%)$ \\
\hline Separada & $2(0,3 \%)$ & $12(0,9 \%)$ & $3(0,4 \%)$ & $11(0,9 \%)$ & $5(0,7 \%)$ & $23(1,6 \%)$ & $5(1,0 \%)$ & $12(0,6 \%)$ & $6(0,8 \%)$ & $20(1,2 \%)$ \\
\hline $\begin{array}{l}\text { União } \\
\text { Consensual }\end{array}$ & $\begin{array}{c}13 \\
(1,8 \%)\end{array}$ & $52(4,1 \%)$ & $30(4,4 \%)$ & $42(3,5 \%)$ & $40(5,9 \%)$ & $80(5,4 \%)$ & $\begin{array}{c}116 \\
(22,8 \%)\end{array}$ & $113(6,0 \%)$ & $59(8,0 \%)$ & $57(3,4 \%)$ \\
\hline Ignorado & $0(0,0 \%)$ & $0(0,0 \%)$ & $6(0,9 \%)$ & $6(0,5 \%)$ & $6(0,9 \%)$ & $7(0,5 \%)$ & $3(0,6 \%)$ & $10(0,5 \%)$ & $0(0,0 \%)$ & $1(0,1 \%)$ \\
\hline TOTAL & $\begin{array}{c}742 \\
(100 \%)\end{array}$ & $\begin{array}{c}1266 \\
(100 \%)\end{array}$ & $\begin{array}{c}687 \\
(100 \%)\end{array}$ & $\begin{array}{c}1187 \\
(100 \%)\end{array}$ & $\begin{array}{c}681 \\
(100 \%)\end{array}$ & $\begin{array}{c}1475 \\
(100 \%)\end{array}$ & $\begin{array}{c}508 \\
(100 \%)\end{array}$ & $\begin{array}{c}1868 \\
(100 \%)\end{array}$ & $740(100 \%)$ & $\begin{array}{c}1692 \\
(100 \%)\end{array}$ \\
\hline
\end{tabular}

Legenda: PC: parto cesário. PN: parto normal. Fonte: DATASUS (2021).

As taxas de cesariana são mais notórios quando a escolaridade é maior e quando a mulher é casada. No estudo realizado por Sass e Hwang (2009) que avaliou o perfil materno das gestantes no ano de 2005 no Brasil avaliou que as mulheres com maior escolaridade e provável melhor condição socioeconômica preferem cesáreas. 
Em conformidade com o estudo de Moreira et al. (2016) que demonstrou maiores taxas de cesariana na faixa etária de 20 a 34 anos, neste trabalho observou-se maior prevalência de partos cesáreos nas faixas etárias dos 20 aos 29 anos.

Observa-se que as gestações pré-termo externo (menos de 28 semanas) apresentam um percentual maior nos partos normais. Entretanto, os valores aparecem semelhantes em ambos os tipos de partos principalmente nas gestações com duração de 37 a 41 semanas.

Quanto ao número de consultas pré-natais as gestações que não tiveram nenhuma consulta apresentaram taxas maiores para parto normal, exemplo disso no ano de 2018, enquanto parto normal sem consulta pré-natal apresentou 2,2\%, o parto cesáreo apresentava $0,2 \%$. As gestações com 1 ou 2 consultas também tiveram valores maiores para o parto normal. Em contraste a esses números, as mulheres que tiveram mais de 7 consultas tiveram como via de parto final o parto cesáreo.

A adequação quantitativa do pré-natal veio para confirmar os dados dos números de consultas pré-natal, uma vez que apresentou percentual que evidenciam gestação que não fizeram o pré-natal ou fizeram o pré-natal de forma inadequada mostram percentuais maiores no parto normal. No ano de 2019, enquanto os partos cesáreos apresentaram o percentual de $16,5 \%$ os partos normais o percentual de 30,9\% em relação ao pré-natal inadequado.

Em relação ao tipo de gravidez, as taxas são semelhantes para os dois tipos de parto prevalecendo o gravidez única. O percentual em relação à gravidez dupla, mostra taxas mais altas para o parto cesareo (Tabela 2). 
Tabela 2. Frequência absoluta e percentual de partos de acordo com as características da gestação por tipo de parto no município de Cáceres-MT, 2015 a 2019.

\begin{tabular}{|c|c|c|c|c|c|c|c|c|c|c|}
\hline \multirow[t]{2}{*}{ Variáveis } & \multicolumn{2}{|c|}{2015} & \multicolumn{2}{|c|}{2016} & \multicolumn{2}{|c|}{2017} & \multicolumn{2}{|c|}{2018} & \multicolumn{2}{|c|}{2019} \\
\hline & PN & PC & PN & PC & PN & PC & PN & PC & PN & PC \\
\hline \multicolumn{11}{|l|}{$\begin{array}{l}\text { Duração da } \\
\text { gestação }\end{array}$} \\
\hline $\begin{array}{l}\text { Menos de } 22 \\
\text { semanas }\end{array}$ & $0(0,0 \%)$ & $0(0,0 \%)$ & $0(0,0 \%)$ & $0(0,0 \%)$ & $1(0,1 \%)$ & $0(0,0 \%)$ & $2(0,4 \%)$ & $0(0,0 \%)$ & $0(0,0 \%)$ & $0(0,0 \%)$ \\
\hline 22 a 27 semanas & $8(1,1 \%)$ & $4(0,3 \%)$ & $\begin{array}{c}12 \\
(1,7 \%)\end{array}$ & $7(0,6 \%)$ & $8(1,2 \%)$ & $6(0,4 \%)$ & $9(1,8 \%)$ & $9(0,5 \%)$ & $12(1,6 \%)$ & $10(0,6 \%)$ \\
\hline 28 a 31 semanas & $\begin{array}{c}13 \\
(1,8 \%)\end{array}$ & $\begin{array}{c}22 \\
(1,7 \%)\end{array}$ & $\begin{array}{c}18 \\
(2,6 \%)\end{array}$ & $22(1,9 \%)$ & $\begin{array}{c}10 \\
(1,5 \%)\end{array}$ & $\begin{array}{c}27 \\
(1,8 \%)\end{array}$ & $9(1,8 \%)$ & $29(1,6 \%)$ & $17(2,3 \%)$ & $43(2,5 \%)$ \\
\hline 32 a 36 semanas & $\begin{array}{c}106 \\
(14,3 \%)\end{array}$ & $\begin{array}{c}228 \\
(18,0 \%)\end{array}$ & $\begin{array}{c}73 \\
(10,6 \%)\end{array}$ & $\begin{array}{c}179 \\
(15,1 \%)\end{array}$ & $\begin{array}{c}80 \\
(11,7 \%)\end{array}$ & $\begin{array}{c}200 \\
(13,6 \%)\end{array}$ & $\begin{array}{c}88 \\
(17,3 \%)\end{array}$ & $\begin{array}{c}330 \\
(17,7 \%)\end{array}$ & $\begin{array}{c}112 \\
(15,1 \%)\end{array}$ & $\begin{array}{c}277 \\
(16,4 \%)\end{array}$ \\
\hline 37 a 41 semanas & $\begin{array}{c}566 \\
(76,3 \%)\end{array}$ & $\begin{array}{c}959 \\
(75,8 \%)\end{array}$ & $\begin{array}{c}561 \\
(81,7 \%)\end{array}$ & $\begin{array}{c}939 \\
(79,1 \%)\end{array}$ & $\begin{array}{c}537 \\
(83,3 \%)\end{array}$ & $\begin{array}{c}1195 \\
(81,0 \%)\end{array}$ & $\begin{array}{c}380 \\
(74,8 \%)\end{array}$ & $\begin{array}{c}1413 \\
(75,6 \%)\end{array}$ & $\begin{array}{c}557 \\
(75,3 \%)\end{array}$ & $\begin{array}{c}1281 \\
(75,7 \%)\end{array}$ \\
\hline 42 semanas ou mais & $\begin{array}{c}48 \\
(6,5 \%)\end{array}$ & $\begin{array}{c}53 \\
(4,2 \%)\end{array}$ & $\begin{array}{c}17 \\
(2,5 \%)\end{array}$ & $29(2,4 \%)$ & $\begin{array}{c}14 \\
(2,1 \%)\end{array}$ & $\begin{array}{c}42 \\
(2,8 \%)\end{array}$ & $\begin{array}{c}19 \\
(3,7 \%)\end{array}$ & $86(4,6 \%)$ & $41(5,5 \%)$ & $81(4,8 \%)$ \\
\hline Ignorado & $1(0,1 \%)$ & $0(0,0 \%)$ & $6(0,9 \%)$ & $11(0,9 \%)$ & $1(0,1 \%)$ & $5(0,3 \%)$ & $1(0,2 \%)$ & $1(0,1 \%)$ & $1(0,1 \%)$ & $0(0,0 \%)$ \\
\hline \multicolumn{11}{|l|}{$\begin{array}{l}\text { Número de } \\
\text { consultas pré-natal }\end{array}$} \\
\hline Nenhuma & $\begin{array}{c}14 \\
(1,9 \%)\end{array}$ & $2(0,2 \%)$ & $\begin{array}{c}14 \\
(2,0 \%)\end{array}$ & $8(0,7 \%)$ & $\begin{array}{c}14 \\
(2,1 \%)\end{array}$ & $3(0,2 \%)$ & $\begin{array}{c}11 \\
(2,2 \%)\end{array}$ & $5(0,3 \%)$ & $14(1,9 \%)$ & $7(0,4 \%)$ \\
\hline 1 a 3 consultas & $\begin{array}{c}103 \\
(13,9 \%)\end{array}$ & $\begin{array}{c}58 \\
(4,6 \%)\end{array}$ & $\begin{array}{c}100 \\
(14,6 \%)\end{array}$ & $67(5,6 \%)$ & $\begin{array}{c}89 \\
(13,1 \%)\end{array}$ & $\begin{array}{c}99 \\
(6,7 \%)\end{array}$ & $\begin{array}{c}86 \\
(16,9 \%)\end{array}$ & $\begin{array}{c}133 \\
(7,1 \%)\end{array}$ & $79(10,7 \%)$ & $129(7,6 \%)$ \\
\hline 4 a 6 consultas & $\begin{array}{c}306 \\
(41,2 \%)\end{array}$ & $\begin{array}{c}426 \\
(33,6 \%)\end{array}$ & $\begin{array}{c}256 \\
(37,3 \%)\end{array}$ & $\begin{array}{c}370 \\
(31,2 \%)\end{array}$ & $\begin{array}{c}265 \\
(38,9 \%)\end{array}$ & $\begin{array}{c}455 \\
(30,8 \%)\end{array}$ & $\begin{array}{c}173 \\
(34,1 \%)\end{array}$ & $\begin{array}{c}549 \\
(29,4 \%)\end{array}$ & $\begin{array}{c}226 \\
(30,5 \%)\end{array}$ & $\begin{array}{c}451 \\
(26,7 \%)\end{array}$ \\
\hline 7 ou mais & $\begin{array}{c}319 \\
(43,0 \%)\end{array}$ & $\begin{array}{c}780 \\
(61,6 \%)\end{array}$ & $\begin{array}{c}313 \\
(45,6 \%)\end{array}$ & $\begin{array}{c}740 \\
(62,3 \%)\end{array}$ & $\begin{array}{c}302 \\
(44,3 \%)\end{array}$ & $\begin{array}{c}915 \\
(62,0 \%)\end{array}$ & $\begin{array}{c}231 \\
(45,5 \%)\end{array}$ & $\begin{array}{c}1170 \\
(62,6 \%)\end{array}$ & $\begin{array}{c}416 \\
(56,2 \%)\end{array}$ & $\begin{array}{c}1105 \\
(65,3 \%)\end{array}$ \\
\hline Ignorado & $0(0,0 \%)$ & $0(0,0 \%)$ & $4(0,6 \%)$ & $2(0,2 \%)$ & $\begin{array}{c}11 \\
(1,6 \%)\end{array}$ & $3(0,2 \%)$ & $7(1,4 \%)$ & $11(0,6 \%)$ & $5(0,7 \%)$ & $0(0,0 \%)$ \\
\hline \multicolumn{11}{|l|}{$\begin{array}{l}\text { Adequação } \\
\text { quantitativa do pré- } \\
\text { natal }\end{array}$} \\
\hline Não fez pré-natal & $\begin{array}{c}14 \\
(1,9 \%)\end{array}$ & $2(0,2 \%)$ & $\begin{array}{c}11 \\
(1,6 \%)\end{array}$ & $4(0,3 \%)$ & $\begin{array}{c}12 \\
(1,8 \%)\end{array}$ & $1(0,1 \%)$ & $\begin{array}{c}10 \\
(2,0 \%)\end{array}$ & $5(0,3 \%)$ & $12(1,6 \%)$ & $6(0,4 \%)$ \\
\hline Inadequado & $\begin{array}{c}259 \\
(34,9 \%)\end{array}$ & $\begin{array}{c}210 \\
(16,6 \%)\end{array}$ & $\begin{array}{c}215 \\
(31,3 \%)\end{array}$ & $\begin{array}{c}218 \\
(18,4 \%)\end{array}$ & $\begin{array}{c}204 \\
(30,0 \%)\end{array}$ & $\begin{array}{c}263 \\
(17,8 \%)\end{array}$ & $\begin{array}{c}187 \\
(36,8 \%)\end{array}$ & $\begin{array}{c}301 \\
(16,1 \%)\end{array}$ & $\begin{array}{c}229 \\
(30,9 \%)\end{array}$ & $\begin{array}{c}279 \\
(16,5 \%)\end{array}$ \\
\hline Intermediário & $\begin{array}{c}93 \\
(12,5 \%)\end{array}$ & $\begin{array}{c}123 \\
(9,7 \%)\end{array}$ & $\begin{array}{c}94 \\
(13,7 \%)\end{array}$ & $\begin{array}{c}126 \\
(10,6 \%)\end{array}$ & $\begin{array}{c}88 \\
(12,9 \%)\end{array}$ & $\begin{array}{c}183 \\
(12,4 \%)\end{array}$ & $\begin{array}{c}65 \\
(12,8 \%)\end{array}$ & $\begin{array}{c}243 \\
(13,0 \%)\end{array}$ & $76(10,3 \%)$ & $\begin{array}{c}228 \\
(13,5 \%)\end{array}$ \\
\hline Adequado & $\begin{array}{c}85 \\
(11,5 \%)\end{array}$ & $\begin{array}{c}193 \\
(15,2 \%)\end{array}$ & $\begin{array}{c}77 \\
(11,2 \%)\end{array}$ & $\begin{array}{c}144 \\
(12,1 \%)\end{array}$ & $\begin{array}{c}85 \\
(12,5 \%)\end{array}$ & $\begin{array}{c}167 \\
(11,3 \%)\end{array}$ & $\begin{array}{c}50 \\
(9,8 \%)\end{array}$ & $\begin{array}{c}198 \\
(10,6 \%)\end{array}$ & $54(7,3 \%)$ & $153(9,0 \%)$ \\
\hline Mais que adequado & $\begin{array}{c}285 \\
(38,4 \%)\end{array}$ & $\begin{array}{c}729 \\
(57,6 \%)\end{array}$ & $\begin{array}{c}278 \\
(40,5 \%)\end{array}$ & $\begin{array}{c}681 \\
(57,4 \%)\end{array}$ & $\begin{array}{c}268 \\
(39,4 \%)\end{array}$ & $\begin{array}{c}851 \\
(57,7 \%)\end{array}$ & $\begin{array}{c}182 \\
(35,8 \%)\end{array}$ & $\begin{array}{c}1105 \\
(59,2 \%)\end{array}$ & $\begin{array}{c}348 \\
(47,0 \%)\end{array}$ & $\begin{array}{c}1019 \\
(60,2 \%)\end{array}$ \\
\hline Não Classificado & $6(0,8 \%)$ & $9(0,7 \%)$ & $\begin{array}{c}12 \\
(1,7 \%)\end{array}$ & $14(1,2 \%)$ & $\begin{array}{c}24 \\
(3,5 \%)\end{array}$ & $\begin{array}{c}10 \\
(0,7 \%)\end{array}$ & $\begin{array}{c}14 \\
(2,8 \%)\end{array}$ & $16(0,9 \%)$ & $21(2,8 \%)$ & $7(0,4 \%)$ \\
\hline \multicolumn{11}{|l|}{ Tipo de gravidez } \\
\hline Única & $\begin{array}{c}729 \\
(98,2 \%)\end{array}$ & $\begin{array}{c}1220 \\
(96,4 \%)\end{array}$ & $\begin{array}{c}677 \\
(98,5 \%)\end{array}$ & $\begin{array}{c}1133 \\
(95,5 \%)\end{array}$ & $\begin{array}{c}675 \\
(99,1 \%)\end{array}$ & $\begin{array}{c}1416 \\
(96,0 \%)\end{array}$ & $\begin{array}{c}498 \\
(98,0 \%)\end{array}$ & $\begin{array}{c}1798 \\
(96,3 \%)\end{array}$ & $\begin{array}{c}731 \\
(\mathbf{9 8 , 8 \%})\end{array}$ & $\begin{array}{c}1623 \\
(95,9 \%)\end{array}$ \\
\hline Dupla & $\begin{array}{c}12 \\
(1,6 \%)\end{array}$ & $\begin{array}{c}46 \\
(3,6 \%)\end{array}$ & $8(1,2 \%)$ & $53(4,5 \%)$ & $6(0,9 \%)$ & $\begin{array}{c}55 \\
(3,7 \%)\end{array}$ & $5(1,0 \%)$ & $68(3,6 \%)$ & $9(1,2 \%)$ & $69(4,1 \%)$ \\
\hline Tripla e mais & $0(0,0 \%)$ & $0(0,0 \%)$ & $0(0,0 \%)$ & $0(0,0 \%)$ & $0(0,0 \%)$ & $0(0,0 \%)$ & $5(1,0 \%)$ & $0(0,0 \%)$ & $0(0,0 \%)$ & $0(0,0 \%)$ \\
\hline Ignorada & $1(0,1 \%)$ & $0(0,0 \%)$ & $2(0,3 \%)$ & $1(0,1 \%)$ & $0(0,0 \%)$ & $4(0,3 \%)$ & $0(0,0 \%)$ & $2(0,1 \%)$ & $0(0,0 \%)$ & $0(0,0 \%)$ \\
\hline TOTAL & $\begin{array}{c}742 \\
(100 \%)\end{array}$ & $\begin{array}{c}1266 \\
(100 \%)\end{array}$ & $\begin{array}{c}687 \\
(100 \%)\end{array}$ & $\begin{array}{c}1187 \\
(100 \%)\end{array}$ & $\begin{array}{c}681 \\
(100 \%)\end{array}$ & $\begin{array}{c}1475 \\
(100 \%)\end{array}$ & $\begin{array}{c}508 \\
(100 \%)\end{array}$ & $\begin{array}{c}1868 \\
(100 \%)\end{array}$ & $\begin{array}{c}740 \\
(100 \%)\end{array}$ & $\begin{array}{c}1692 \\
(100 \%)\end{array}$ \\
\hline
\end{tabular}

Legenda: PC: parto cesário. PN: parto normal. Fonte: DATASUS (2021).

A consulta de pré-natal é a principal maneira de assegurar o desenvolvimento de qualidade da gestação, pois possibilita o acompanhamento da gestante e do desenvolvimento do feto, diminuindo os riscos para mortalidade materna e infantil (Guimarães et al., 2017) . Nos dados avaliados a idade gestacional mais prevalente em ambos os partos foi de 37 a 41 semanas, esse padrão não divergiu do que foi encontrado no estudo realizado por Dantas e Costa (2019) no estado de Sergipe , sendo esse intervalo de tempo considerado o mais adequado para o nascimento do bebê.

Relacionado à análise do estudo referente à quantidade de consultas realizadas, foi verificado que são realizadas sete ou mais consultas principalmente nos partos cesáreos. Os partos normais têm uma taxa maior quanto o número de consultas são menores. O estudo realizado por Lopes (2021) corrobou com a correlação entre cesarianas e o número de consultas maiores que sete. 
A contrariedade entre o número de consultas pré-natal e adequação quantitativa do pré-natal se dá pois o Ministério da Saúde faz um levantamento extensivo dos indicadores que possibilitam avaliar acesso ao pré-natal. Assim, levando em consideração ao que é exposto como boa prática nos documentos da Rede Cegonha - início do pré-natal no primeiro trimestre e um mínimo de seis consultas de pré-natal -, o taxa é calculada a partir dos campos "33 - Número de consultas pré-natal" (Mesprenat) e "34 - Mês de gestação em que iniciou o pré-natal" (Consprenat), por esse motivo a maioria dos estudos que descrevem o perfil de nascimento excluem a variavel de adequação quantitativa do pré-natal.

O tipo de gravidez independente do parto foi muito superior na gestação única, porém esse número não é significativo uma vez que a gestação única é a mais comum.

O local de ocorrência prevalecente no município de Cáceres foi o hospital em ambos tipos de parto, o que já era esperado uma vez que é o local onde ocorre a assistência médica. Ainda que o parto normal possa ser conduzido em casa, a maioria das mães o realizaram no hospital, no ano de 2017 foi quando teve maior número (9) de partos domiciliares. (Figura 2).

Figura 2. Local de ocorrência por parto normal (A) e parto cesáreo (B), em Cácere-MT, 2015 a 2019.

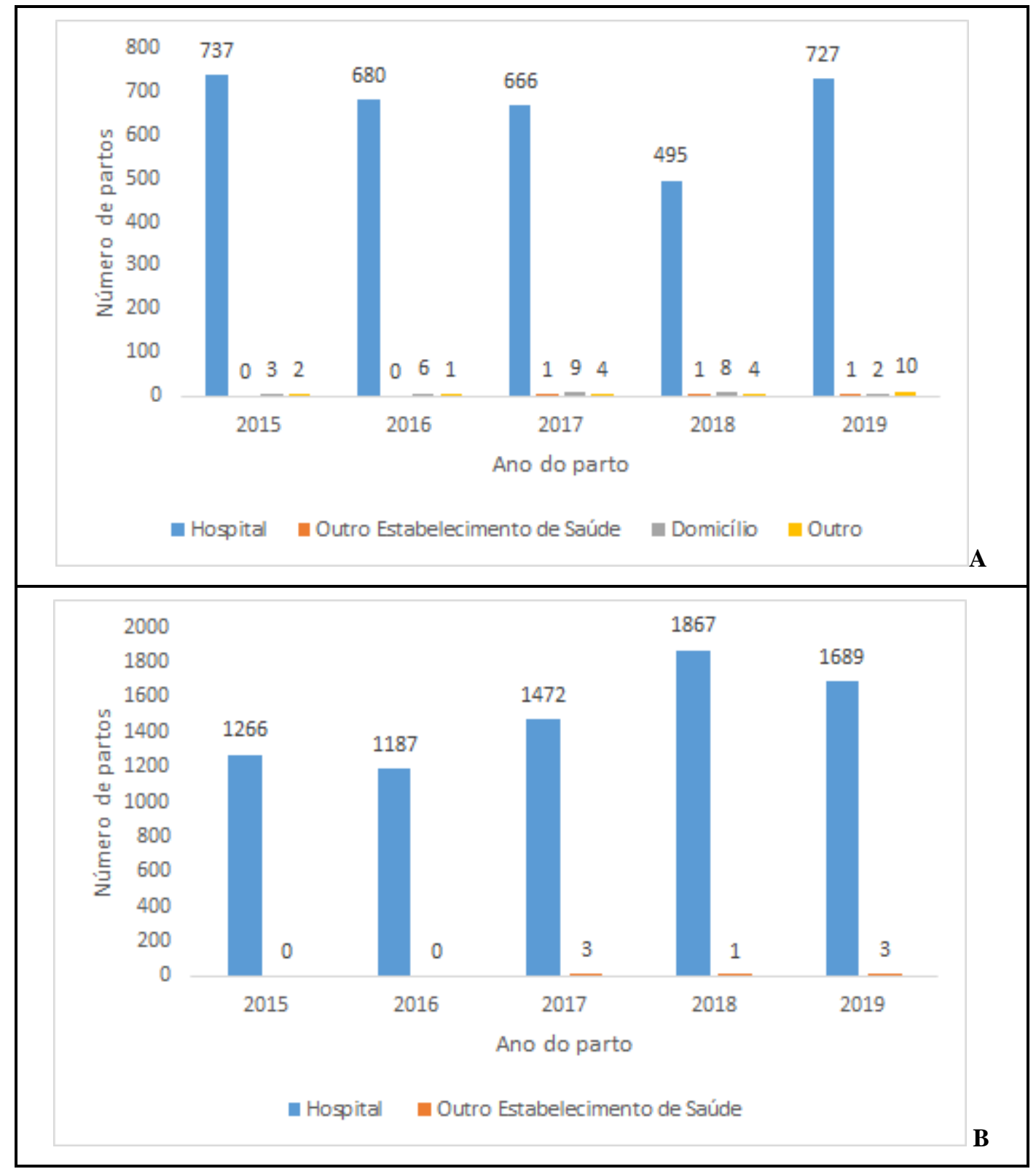

Fonte: DATASUS (2021). 
As gestantes de baixo risco podem escolher pelo parto domiciliar ou pela assistência hospitalar de curta duração, onde serão assistidas de acordo com o nível do risco. Na Holanda, 70\% dos partos são assistidos pelas parteiras (ao aposto dos EUA com 7\%) e os outros 30\% são assistidos por obstetras. Dos partos assistidos pelas enfermeiras, $60 \%$ são assistidos no domicílio e $40 \%$ no hospital, o que significa $31,8 \%$ de partos domiciliares. A Holanda é vista referencia no modelo de assistência com forte presença das enfermeiras obstetras e com bons resultados. (Borquez \& Wiegers, 2006)

Os municípios com valor positivo são os que realizam os partos na cidade. Uma vez que Cáceres-MT dispõe do Hospital São Luiz, o mesmo recebe diariamente pacientes de outros municípios principalmente para partos de alto risco e por essa razão possui número positivo tão alto com uma média de 591 partos advindos de outros municípios no período analisado. O município de São José dos Quatro Marcos também apresenta valores positivos em todos os anos, se destacando como local de ocorrência de partos. Araputanga e Vila Bela da Santissíma Trindade apresentaram valores positivos em anos anteriores, mas voltaram a fazer encaminhamentos e Pontes e Lacerda apresenta os anos de 2018 e 2019 valores positivos. Os municípios com valor negativos são aqueles que encaminham todos os partos (Tabela 3). 
Tabela 3. Número de parto por local de residência e por local de ocorrência dos municípios que fazem parte da região de referência para partos na cidade de Cáceres, 2015 a 2019.

\begin{tabular}{|c|c|c|c|c|c|c|c|c|c|c|c|c|c|c|c|}
\hline \multirow[t]{2}{*}{ Município } & \multicolumn{5}{|c|}{$\begin{array}{c}\text { Número de partos por local de } \\
\text { residência }\end{array}$} & \multicolumn{5}{|c|}{$\begin{array}{l}\text { Número de partos por local de } \\
\text { ocorrência }\end{array}$} & \multicolumn{5}{|c|}{$\begin{array}{c}\text { Diferença entre local de ocorrência } \mathrm{x} \\
\text { residência }\end{array}$} \\
\hline & 2015 & 2016 & 2017 & 2018 & 2019 & 2015 & 2016 & 2017 & 2018 & 2019 & 2015 & 2016 & 2017 & 2018 & 2019 \\
\hline Araputanga & 245 & 239 & 267 & 246 & 257 & 219 & 314 & 276 & 263 & 243 & -26 & 75 & 9 & 17 & -14 \\
\hline Cáceres & 1563 & 1446 & 1567 & 1658 & 1663 & 2008 & 1877 & 2157 & 2376 & 2432 & 445 & 431 & 590 & 718 & 769 \\
\hline Campos de Júlio & 145 & 123 & 135 & 143 & 126 & 89 & 96 & 84 & 50 & 6 & -56 & -27 & -51 & -93 & -120 \\
\hline Comodoro & 337 & 390 & 388 & 368 & 364 & 238 & 284 & 313 & 287 & 281 & -99 & -106 & -75 & -81 & -83 \\
\hline $\begin{array}{l}\text { Conquista } \\
\text { D'Oeste }\end{array}$ & 56 & 43 & 58 & 67 & 65 & 0 & 3 & 4 & 1 & 3 & -56 & -40 & -54 & -66 & -62 \\
\hline Curvelândia & 68 & 62 & 65 & 64 & 69 & 1 & 1 & 0 & 0 & 0 & -67 & -61 & -65 & -64 & -69 \\
\hline $\begin{array}{l}\text { Figueirópolis } \\
\text { D'Oeste }\end{array}$ & 46 & 41 & 46 & 62 & 52 & 0 & 0 & 0 & 0 & 0 & -46 & -41 & -46 & -62 & -52 \\
\hline Glória D'Oeste & 24 & 35 & 41 & 35 & 30 & 0 & 0 & 0 & 0 & 0 & -24 & -35 & -41 & -35 & -30 \\
\hline Indiavaí & 35 & 30 & 37 & 33 & 47 & 0 & 0 & 1 & 0 & 0 & -35 & -30 & -36 & -33 & -47 \\
\hline Jauru & 150 & 130 & 129 & 111 & 128 & 49 & 29 & 21 & 23 & 14 & -101 & -101 & -108 & -88 & -114 \\
\hline $\begin{array}{l}\text { Lambari } \\
\text { D'Oeste }\end{array}$ & 58 & 76 & 75 & 96 & 75 & 1 & 0 & 2 & 1 & 1 & -57 & -76 & -73 & -95 & -74 \\
\hline Mirassol d'Oeste & 452 & 394 & 407 & 405 & 454 & 537 & 346 & 384 & 283 & 398 & 85 & -48 & -23 & -122 & -56 \\
\hline Nova Lacerda & 77 & 60 & 94 & 81 & 86 & 0 & 0 & 2 & 0 & 3 & -77 & -60 & -92 & -81 & -83 \\
\hline $\begin{array}{l}\text { Pontes e } \\
\text { Lacerda }\end{array}$ & 824 & 742 & 844 & 862 & 839 & 800 & 711 & 824 & 972 & 965 & -24 & -31 & -20 & 110 & 126 \\
\hline Porto Esperidião & 169 & 167 & 200 & 151 & 168 & 5 & 6 & 4 & 3 & 9 & -164 & -161 & -196 & -148 & -159 \\
\hline $\begin{array}{l}\text { Reserva do } \\
\text { Cabaçal }\end{array}$ & 37 & 17 & 31 & 36 & 23 & 0 & 0 & 0 & 0 & 0 & -37 & -17 & -31 & -36 & -23 \\
\hline Rio Branco & 89 & 55 & 83 & 88 & 86 & 46 & 30 & 25 & 23 & 22 & -43 & -25 & -58 & -65 & -64 \\
\hline Rondolândia & 29 & 49 & 32 & 24 & 25 & 0 & 0 & 0 & 0 & 1 & -29 & -49 & -32 & -24 & -24 \\
\hline Salto do Céu & 57 & 55 & 42 & 54 & 58 & 32 & 40 & 42 & 39 & 9 & -25 & -15 & $\mathbf{0}$ & -15 & -49 \\
\hline $\begin{array}{l}\text { São José dos } \\
\text { Quatro Marcos }\end{array}$ & 282 & 210 & 265 & 277 & 233 & 465 & 387 & 401 & 359 & 316 & 183 & 177 & 136 & 82 & 83 \\
\hline $\begin{array}{l}\text { Vale de São } \\
\text { Domingos }\end{array}$ & 36 & 36 & 34 & 38 & 51 & 1 & 0 & 0 & 1 & 0 & -35 & -36 & -34 & -37 & -51 \\
\hline $\begin{array}{l}\text { Vila Bela da } \\
\text { Santíssima } \\
\text { Trindade }\end{array}$ & 258 & 256 & 283 & 261 & 269 & 315 & 318 & 332 & 215 & 234 & 57 & 62 & 49 & -46 & -35 \\
\hline
\end{tabular}

Fonte: DATASUS (2021).

Não cabe ao médico plantonista questionar o encaminhamento do médico que acompanhou o pré-natal para a maternidade de alto risco, a gestante precisa ter seus direitos assegurados no momento do parto independente do município. Assim, o Ministério da Saude (2005) afirmar que é necessário identificar os riscos aos quais cada gestante está exposta afim de orientar e encaminhar de forma adequada em cada momento da gravidez, sendo indispensável que essa avaliação do risco seja permanente, ou seja, aconteça em toda consulta. 
Uma vez a mulher é encaminhada para outro município e não sabe onde vai acontecer o parto faz com que o desconhecimento do histórico gestacional e a pressa influencie negativamente para o parto, uma vez que essas transferências ocorrem principalmente em partos de urgência (UNICEF,2011).

Destaca-se que alguns municípios da regional de Cáceres aparecem como locais que estão realizando os partos, como São José dos Quatro Marcos, Pontes e Lacerda e Vila Bela da Santíssima Trindade, esses municípios merecem ser acompanhados e comparados os perfis em estudos no futuro, uma vez que esses locais não tem estrutura para atendimento de alto risco.

Para partos normais o grupo da escala de Robson com mais prevalência durante todos os anos foi o grupo 3, todos os anos acima de 30\% dos partos normais. O grupo 1 também apresentou percentuais acima de 15\% durante todos os anos, assim como o grupo 10. Os grupos 4,5 e 2 apresentaram percentais abaixo de $10 \%$. Os grupos 6,7 e 8 percentuais abaixo de $5 \%$ e o grupo 9 não apresentou nenhum percentual (Figura 3).

Figura 3. Distribuição das partos normais nos grupos de Robson, realizados em Cáceres-MT, 2015 a 2019.

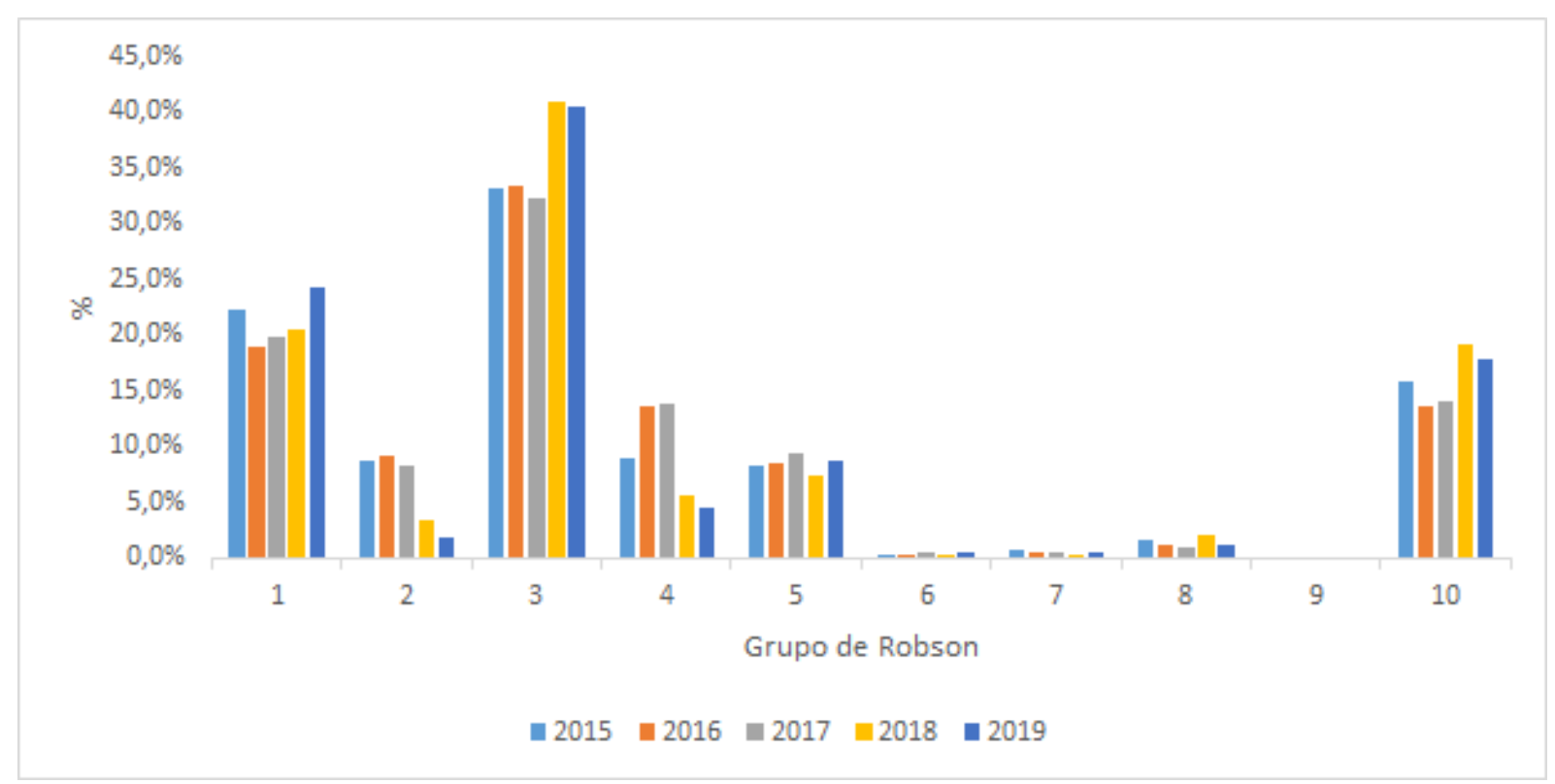

Legenda: Grupo 1: nulíparas, feto único cefálico, $\geq 37$ semanas, em trabalho de parto espontâneo; Grupo 2: nulíparas, feto único cefálico, $\geq 37$ semanas, indução ou cesariana antes do trabalho de parto; Grupo 3: multíparas, sem cesárea prévia, feto único cefálico, $\geq 37$ semanas, em trabalho de parto espontâneo; Grupo 4: multíparas, sem cesárea prévia, feto único cefálico, $\geq 37$ semanas, indução ou cesariana antes do trabalho de parto; Grupo 5: cesárea anterior, feto único cefálico, $\geq 37$ semanas; Grupo 6: nulíparas com feto em apresentação pélvica, incluindo cesárea prévia ; Grupo 7: multíparas com feto em apresentação pélvica, incluindo cesárea prévia; Grupo 8: gravidez múltipla, incluindo cesárea prévia; Grupo 9: feto em apresentação córmica, incluindo cesárea prévia; Grupo 10: gravidez <37 semanas, feto único cefálico, incluindo cesárea prévia. Fonte: DATASUS (2021).

Os partos vaginais apresentam as maiores taxas para os grupos 3 e 1, esses grupos contabilizam as mulheres multíparas e nulíparas, com gestação única cefálica, sem cesárea anterior, $\geq 37$ semanas de gestação e em trabalho de parto espontâneo. Analogo a esses resultados o estudo feito em Ceára apresentou maiores contribuições a taxa global de partos vaginais nos grupos 3 e 1 com 35,7\% e 21,0\% respectivamente (Moura, 2017).

A taxa do grupo 10 era esperada para Cáceres por dispor de um hospital de referência e poder dar suporte aos fetos pré-termos e assemelha-se a taxa apresentada em Ceára uma vez que o hospital em análise era um hospital universitário terciário de referência (Moura, 2017).

É necessario atentar-se para os grupos 2 e 4 pois as taxas de partos vaginais foram baixas. Os grupos 2 e 4 englobam as mulheres nulíparas e multíparas com gestação única cefálica, $\geq 37$ semanas de gestação, que tiveram parto induzido ou foram para cesariana antes do início do trabalho de parto, tais números indicam a necessidade de se rever as atuais indicações e formas de indução do trabalho de parto, assim como as reais indicações de cesárea nessas mulheres 
Com relação à taxa do grupo 5 para os partos vaginais, observa-se que a prática clínica de parto vaginal após cesariana ainda é pouco adotada. O American College of Obstetricians and Gynecologists (2010) relata que, dos casos de partos vaginais após cesariana (VBAC, sigla em inglês), de $60 \%$ a $80 \%$ pode resultar em um parto bem sucedido, reduzindo a morbidade materna e a taxa de complicações.

As maiores taxas nos partos cesáreos seguindo a escala de Robson foram dos grupos 5, 1 e 10, respectivamente. Os gruos 2,3 e 4 apresentaram percentais abaixo de $10 \%$ durante os anos. Os grupos 8,7 e 6 os percentuais foram menores que $5 \%$ e o grupo 9 apresentou o menor percentual (Figura 4).

Figura 4. Distribuição dos partos cesáreos nos grupos de Robson, realizados em Cáceres-MT, 2015 a 2019.

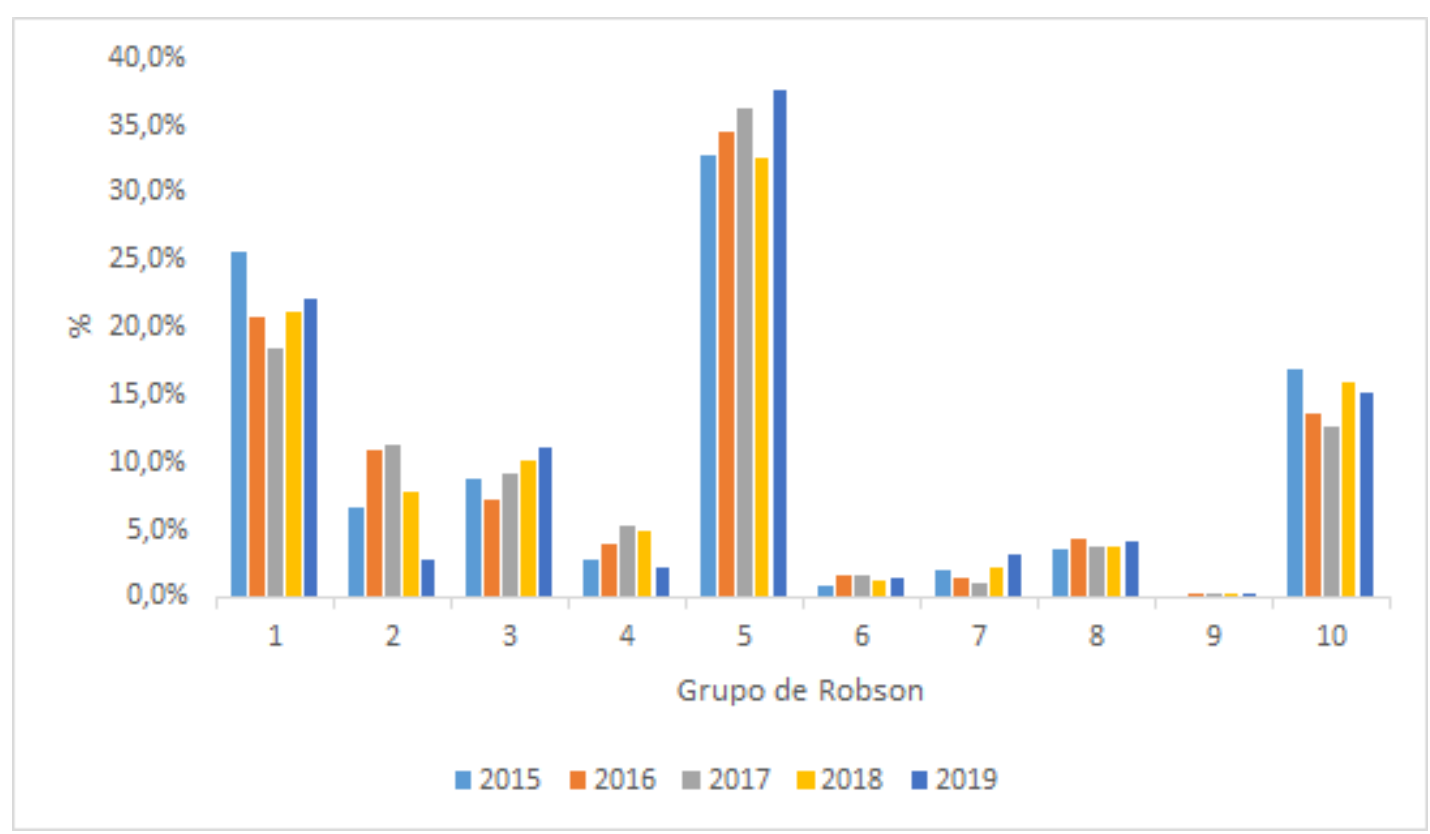

Legenda: Grupo 1: nulíparas, feto único cefálico, $\geq 37$ semanas, em trabalho de parto espontâneo; Grupo 2: nulíparas, feto único cefálico, $\geq 37$ semanas, indução ou cesariana antes do trabalho de parto; Grupo 3: multíparas, sem cesárea prévia, feto único cefálico, $\geq 37$ semanas, em trabalho de parto espontâneo; Grupo 4: multíparas, sem cesárea prévia, feto único cefálico, $\geq 37$ semanas, indução ou cesariana antes do trabalho de parto; Grupo 5: cesárea anterior, feto único cefálico, $\geq 37$ semanas; Grupo 6: nulíparas com feto em apresentação pélvica, incluindo cesárea prévia ; Grupo 7: multíparas com feto em apresentação pélvica, incluindo cesárea prévia; Grupo 8: gravidez múltipla, incluindo cesárea prévia; Grupo 9: feto em apresentação córmica, incluindo cesárea prévia; Grupo 10: gravidez <37 semanas, feto único cefálico, incluindo cesárea prévia. Fonte: DATASUS (2021).

O grupo 5, correspondente ao grupo de multíparas a termo, fetos cefálicos, submetidas a cesariana anterior, e apresentam o maior número de pacientes, o que está de acordo com as literaturas atuais (Kelly et al, 2013; Betrán et al, 2014). Esta informação é relevante para que sejam tomadas medidas que reduzam a quantidade de cesarianas desnecessárias, com foco principalmente nas nulíparas a termo submetidas a cesarianas, com fetos em apresentação cefálica, após início espontâneo do trabalho de parto (grupo 1). Permite, além disso, a elaboração de protocolos clínicos para que seja encorajada a realização de parto vaginal após cesariana, tendo em vista que as grandes taxas de cesárea nos grupos 1 e 2 afetam, no futuro, o grupo 5 .

O estudo realizado por Freitas e Vieira (2020), mostrou que o grupo 5 foi responsável pela maior contribuição nas taxas de cesariana em Santa Catarina. Isso chama a atenção para denominado "efeito dominó" levantado pela OMS, que corresponde a taxas crescentes de cesárea entre as primíparas e consequente acúmulo de mulheres com cesariana prévia, potencialmente sujeitas a um maior risco de uma nova cesariana (Nakamura-Pereira, 2018)

Os grupos 5, 10 e 2 também foram os grupos com maior contribuição para os partos cesários nos dados obtidos através do estudo produzido por Soares et al. (2021) no municipio de Santa Maria no interior do estado de Rio Grande do Sul.

Nos grupos 6 e 7 a apresentação fetal determina as decisões obstétricas. A soma de suas taxas deve ser de 3-4\%, obtendo-se nesse trabalho entre 0,9 e 3,1\%, o que está dentro da margem esperada para apresentação pélvica. Comparando 
com os EUA as taxas se assemelham com as taxas entre 1,1\% e 3,3\% (Rudey, 2020) e entre as regiões do Brasil variam entre $2,1 \%$ e $3,4 \%$ (Knobel, 2020).

O tamanho do grupo 8 foi entre 3,6\% e 4,4\%. Sua contribuição deve ser de 1,5 a 2\%, porém os números nesta amostra foi superior à esperada por Cáceres dispor de hospital de referência e alto risco para toda região. Em comparação a outros estudos realizados do Brasil, há semelhança entre o resultado encontrado uma vez que os estudos trazem taxas de $3,2 \%$ no estado do Rio de Janeiro (Alcantara et al., 2020) e nos países do exterior seguem o mesmo percentual 2,6\% a 2,7\% nos EUA e 3,27\% no Peru (Hehir, 2018; Rudey, 2020)

Observa-se que o tamanho do grupo 9 para PC está dentro da margem esperada $(0,1 \%-0,3 \%)$ e a taxa de cesáreas no grupo sugere que a classificação foi feita de forma adequada, uma vez que se o feto estiver em situação transversal durante o trabalho de parto indica uma indicação real de cesárea.

A taxa do grupo 10 foi entre $12,7 \%$ e $16,8 \%$. Sua taxa deve ser inferior a $5 \%$, mas justifica-se novamente a atribuição superior obtida pelo município de Cáceres sua característica de possuir o hospital São Luiz que é referência, contando com UTIs materna e neonatal, o que leva ao encaminhamento de pacientes com patologias graves. Comparando com o estudo realizado num hospital terciário que dispõe de serviços para urgência obstétrica em Portugal apresentou taxa de 10,4\%, enquanto Hospital Universidade de Santa Maria que também é referencial em alto risco teve taxa de 8,9\%. (Vargas, 2020; Soares, 2021)

O grupo 1 foi o segundo mais prevalente, dentro desse grupo, as principais indicações que levariam ao parto cesáreo são: prolapso de cordão, descolamento prematuro da placenta com feto vivo, placenta prévia parcial ou total, apresentação córmica, ruptura de vasa praevia, herpes genital com lesão ativa, HIV/Aids e sofrimento fetal agudo. (Amorim, Souza \& Porto, 2011) Assim pode-se sugerir que no município em questão, estas intercorrências têm alta incidência, além de podermos questionar quanto à referência das gestantes de alto risco das cidades vizinhas optaram por parir no Hospital São Luiz visto que tais indicações são comuns em maternidades de alto risco.

As limitações do estudo se referem à análise não ser realizada por local de residência, somente por local de ocorrência, impossibilitando avaliar a assistência pré-natal, e foi realizado a avaliação apenas do munícipio de Cáceres. Os dados utilizados neste estudos são de fonte secundária, sendo que podem apresentar problemas de interpretação no preenchimento das declarações de nascidos vivos e no momento da digitação para o sistema, uma vez que o preenchimento desse documento ainda é manual.

Como contribuição, essa análise visa ajudar os serviços de saúde a identificar os grupos de mulheres que mais contribuem para as taxas gerais de cesarianas, incentivar mudanças no manejo desses grupos na prática clínica e reduzir as taxas desnecessárias de cesarianas.

\section{Conclusão}

A pesquisa permitiu observar que na cidade de Cáceres-MT houve um predomínio do parto cesáreo em todos os anos de análise.

O perfil das puérperas de parto cesáreo evidenciou mulheres de 20 a 34 anos, com 8 a 11 anos de escolaridade e solteira, em relação ao perfil obstétrico a duração da gestação foi entre 37 á 41 semanas, realizando 7 ou mais consultas e com adequação quantitativa do pré-natal mais do que adequada. Os grupos de Robson com maiores taxas para os partos cesáreos foram os grupos 5,1 e 10 , respectivamente.

Já o perfil das mulheres de parto normal prevaleceu mulheres de 15 a 24 anos, com 8 a 11 anos de escolaridade e solteiras, quanto ao perfil obstétrico a duração da gestação foi entre 37 á 41 semanas, realizando 7 ou mais consultas e com adequação quantitatica do pré-natal dividido entre inadequado e mais do que adequado. Os grupos de Robson com maiores 
contribuições para este tipo de parto foram os grupos 3, 1 e 10, respectivamente.

Diante disso, este estudo permitiu traçar o perfil socioeconômico e obstétrico das puérperas usuarias do serviço obstétrico do municipio de Cáceres, dessa forma, posibilitou também avaliar pela classificação de Robson que a maioria da população estudada é elegível para o parto normal conforme seu perfil obstétrico, sendo fundamental profissionais capacitados e condições adequadas para que isso ocorra.

\section{Referências}

ACOG - American College of Obstetricians and Gynecologists. (2010). Practice bulletin no.115: Vaginal birth after previous cesarean delivery. Obstet Gynecol, 116(2): 450-463

Alcantara, L. L. M., Almeida, N. K. O. \& Almeida, R. M. V. R. (2020). Pattern of Live Births in Rio de Janeiro State, Brazil, According to Robson Groups and the Kotelchuck Index Classification - 2015/2016. Rev Bras Ginecol Obstet,42(7):373-379.

Amorim, M. M. R., Souza, A. S. R., \& Porto, A. M. F. (2010). Indicações de cesariana baseadas em evidências: parte I. Femina. ,38(8):415-422.

Betrán, A. P. \& et al. (2014). A systematic review of the Robson Classification for cesarean section: What works, doesn't work and how to improve it. PLoS One, 9(6): e97769.

Borquez, H. A. \& Wiegers, T. A. (2006) A comparison of labour and birth experiences of women delivering in a birthing centre and at home in the Netherlands. Midwifery, 22(4):339-47.

Brasil. (2005). Ministério da Saúde. Programa de Assistência Integral à Saúde da Mulher: bases de ação programática.

Chiavegatto filho, A. D. P. (2013). Partos cesáreos e a escolha da data de nascimento no Município de São Paulo. In: Ciência \& Saúde Coletiva. Associação Brasileira de Saúde Coletiva, 18(8), 2413-2420.

Dantas, S. J. \& Costa, S. M. (2019). Perfil epidemiológico de partos e nascimentos do estado de Sergipe: análise de dados secundários. 23 f. TCC (GRADUAÇÃO) - Curso de enfermagem, Coordenação de enfermagem, Universidade Tiradentes, Aracajú-SE.

Freitas, P. F. \& Vieira, H. G. M. (2020). Uso do Sistema de Classificação de Robson na avaliação das taxas de cesariana em Santa Catarina e sua associação com perfil institucional. J. Health Biol Sci., 8(1): 1-9.

Fujita, J. A. L. M. \& Shimo, A. K. K. (2014). Parto humanizado: experiências no sistema único de saúde. Revista Mineira de Enfermagem, 18(4), 1-5.

Fundação Oswaldo Cruz. (2018). Instituto Nacional de Saúde da Mulher, da Criança e do Adolescente Fernandes Figueira. Classificação de Robson.

Gama, S. G. N. \& et al. (2014). Fatores associados à cesariana entre primíparas adolescentes no Brasil, 2011-2012. Cadernos de Saúde Pública, 30, S117S127.

Guimarães, R. M. \& et al. (2017). Fatores associados ao tipo de parto em hospitais públicos e privados no Brasil. Rev. Bras. Saúde Matern. Infant.,17 (3): 581 590 .

Hehir M. P. \& et al. (2018). Cesarean delivery in the United States 2005 through 2014: a population-based analysis using the Robson 10-Group Classification System. American Journal of Obstetrics \& Gynecology, 219:105.e1-11

Kelly, S. \& et al. (2013) Examining Caesarean Section Rates in Canada Using the Robson Classification System. J Obstet Gynaecol Can, 35(3), 206-214.

Knobel, R. \& et al. (2020). Cesarean-section Rates in Brazil from 2014 to 2016: Cross-sectional Analysis Using the Robson Classification. Rev Bras Ginecol Obstet, 42(9):522-528.

Lopes, D. L. \& et al. (2021) Perfil de partos e nascimentos na baixada Maranhense. Revista Eletrônica Acervo Saúde, $13(5)$, e7297.

Marques, F. C., Dias, I. M. V. \& Azevedo, L. A. (2006). Percepção da equipe de Enfermagem sobre Humanização do Parto e Nascimento. Esc Anna Nery R Enferm., 10 (3): 439- 47.

Martins, A. P. C., Jesus, M. V. N., Prado Júnior, P. P. \& Passos, C. M. (2018). Aspectos que influenciam a tomada de decisão da mulher sobre o tipo de parto. Rev baiana enferm., 32:e25025.

Medina, E. T. (2003). Tecnologias de cuidado de enfermagem obstétrica e seus efeitos sobre o trabalho de parto: um estudo exploratório. Dissertação (Mestrado) do Programa de Pós-Graduação em Enfermagem da Universidade do Estado do Rio de Janeiro, Rio de Janeiro, 2003.

Moreira, B. R. \& et al. (2016). Determinantes relacionados ao parto cesáreo em maternidade pública da Região Metropolitana de Belo Horizonte-MG. Rev Med Minas Gerais, 26:e-1799

Moura, V. A. \& Feitosa, F. E. L. (2017). Avaliação de cesáreas na Maternidade Escola Assis Chateaubriand utilizando o Sistema de Classificação de Robson em Dez Grupos. Rev Med UFC, 57(1), 25-29.

Nakamura-Pereira, M., Esteves-Pereira, A., Gama, S. \& Leal, M. (2018). Elective repeat cesarean delivery in women eligible for trial of labor in Brazil. Int Journal of Gyn \& Obst.,143(3):351-359. 
Research, Society and Development, v. 11, n. 1, e8111124663, 2022

(CC BY 4.0) | ISSN 2525-3409 | DOI: http://dx.doi.org/10.33448/rsd-v11i1.24663

Nakano, R. A., Bonan, C. \& Teixeira, A. L. (2016). Cesárea, aperfeiçoando a técnica e normatizando a prática: uma análise do livro Obstetrícia, de Jorge de Rezende. Hist. ciênc. Saúde-Manguinhos, 23(1), 155 - 172.

Organização Mundial da Saúde. (2015). Declaração da $\quad$ OMS $\quad$ sobre $\quad$ Taxas $\quad$ de $\quad$ Cesáreas. http://apps.who.int/iris/bitstream/10665/161442/3/WHO_RHR_15.02_por.pdf.

Organização Mundial de Saúde. (1996). Assistência ao parto normal: um guia prático. Saúde materna e neonatal. Unidade de maternidade segura. Saúde reprodutiva e da família.

Patah, L. E. M. \& Malik, A. M. (2011). Modelos de assistência ao parto e taxa de cesárea em diferentes países. Revista de Saúde Pública, 45(1), 185-194.

Pereira, S. S. \& et al. (2016). Parto natural: a atuação do enfermeiro diante da assistência humanizada. Revista Tempus, 10(3), 199-213.

Pinto, K.C.L.R. (2020). Avaliação de gestantes admitidas em um hospital público segundo a classificação de Robson. Braz. J. of Develop, 6(9), 67660-67670

Rudey, E. L., Leal, M. C. \& Rego, G. (2020). Cesarean section rates in Brazil. Trend analysis using the Robson classification system. Medicine, 99(17).

Sass, N. \& Hwang, S. M. (2009). Dados epidemiológicos, evidências e reflexões sobre a indicação de cesariana no Brasil. Diagn Tratamento,14(4):133-

Soares, B. S. \& et al. (2021). Gestational Risk as a Determining Factor for Cesarean Section according to the Robson Classification Groups. Rev Bras Ginecol Obstet,43(2):84-90

UNICEF, Fundo das Nações Unidas para a Infância. (2011). Guia dos Direitos da Gestante e do Bebê. Globo.

Vargas, S., Rego, S. \& Clode, N. (2020). Cesarean Section Rate Analysis in a Tertiary Hospital in Portugal According to Robson Ten Group Classification System. Rev Bras Ginecol Obstet,42(6):310-315.

Ye, J., Betrán, A. P., Guerrero Vela, M., Souza, J. P. \& Zhang, J. (2014). Searching for the optimal rate of medically necessary cesarean delivery. Birth. 41(3):237-44 